\section{THU0269 DEVELOPMENT OF ANKYLOSING SPONDYLITIS IN PATIENTS WITH REACTIVE ARTHRITIS AND PERIPHERAL SPONDYLOARTHROPATHY: HOSPITAL BASED STUDY IN NORTH INDIA}

R. Misra, S. Ahmed, A. Chaudhury, A. Lawrence, V. Agarwal, A. Aggarwal. Clinical Immunology, Sanjay Gandhi Post Graduate Institute of Medical Sciences, Lucknow, India

Background: Reactive arthritis $(\operatorname{Re} A)$ is a seronegative spondyloarthropathy $(\mathrm{SpA})$ that is precipitated by urogenital or gastrointestinal infection. Undifferentiated Peripheral spondyloarthropathy (UpSpA) may be indistinguishable from $\operatorname{ReA}$ except known preceding infection. It is stated that two-thirds of ReA resolve within three months while a third develop chronic or recurrent course. However, there is a paucity of data on the long-term outcome. Thus, it is difficult to justify treatment decisions like the use of biologicals in $\operatorname{ReA}$

Objectives: To determine the outcome of ReA/upSpA patients attending a referal rheumatology centre in North India.

Methods: ReA was classifed as per Braun's criteria, while UpSpA were included as meeting ASAS criteria but not criteria for psoriatic arthrtis or inflammatory bowel disease associated arthritis. Data on this retrospective cohort was updated with telephonic interviews. Follow-up of less than 1 year were excluded. Patients with persistent inflammatory back pain (IBP) were reviewed in the clinic. Radiographs assessed progression to AS (modified New York criteria).

Results: Follow-up data on 85 patients ( $63 \mathrm{ReA} ; 22 \mathrm{pSpA}$ ) was obtained. Median (IQR) age at presentation was $24.5(20-33)$ years. $14(16.5 \%)$ were female. At presentation, $23(30 \%)$ had monoarthritis, $44(57 \%)$ had oligoarthritis, $10(13 \%)$ had polyarthritis (data missing for eight). Enthesitis and dactylitis were documented in 20 and 5 respectively. Keratoderma and balanitis were seen in one each. $40(80 \%)$ out of 50 were positive for HLA-B27.

Median (IQR) follow-up was 2 (1-5.25) years. 22 had monophasic illness of which 13 had acute arthritis $(<12$ weeks). Seven had two episodes, 27 had polycyclic course while 29 had persistent arthritis. 26 had inflammatory back pain (IBP) at any time and eight had persistent symptoms. Out of these, three (3.5\%) met criteria for AS (disease duration: 1, 3 and 10 years) while two had unilateral grade 2 sacroilitis. Three patients without IBP also had sacroilitis on radiographs. Logistic regression revealed no significant parameter that could predict progression to AS Conclusions: In contrast to general opinion that two thirds attend remission, this study showed that one third undergo drug free remisson. Of the remaining, half deveop recurrent and half persistent arthritis. 3.5\% progressed to AS. As duration of follow-up increases, a greater proportion may progress to AS.

\section{REFERENCES:}

[1] Brinster A, Guillot X, et al. Evolution over thirty years of the profile of inpatients with reactive arthritis in a tertiary rheumatology unit. Reumatol. Clin 2016.

[2] Leirisalo-Repo M, et al. Long-term prognosis of reactive salmonella arthritis. Ann. Rheum. Dis 1997:56,516-520.

[3] Kaarela K, et al. Similarity between chronic reactive arthritis and ankylosing spondylitis.A 32-35-year follow-up study. Clin. Exp. Rheumatol 2009;27:325-328

Disclosure of Interest: None declared

DOI: 10.1136/annrheumdis-2018-eular.6558

\section{THU0270 THE PROPENSITY TO FAT METAPLASIA OF SACROILIAC JOINT IN SPONDYLOARTHROPATHY: RESULTS FROM THE SINGLE REGIONAL CENTRECOHORT}

S.Y. Lee, S.W. lee, W.T. chung, J.W. jung. Rheumatology Of Internal Medicine, Dong-a University Hospital, Pusan, Korea, Republic of Ireland

Background: The predictor of radiographic spinal progression is the presence of syndesmophytes at baseline in axial spondyloarthritis (axSpA) and fat metaplasia on spine maybe predict the formation of new syndemophytes. Some studies suggests that fat metaplasia maybe a potential starting point for new bone formation and have a general systemic effect on new bone formation in spine, rather than results from local inflammation. Recent studies suggest that fat metaplasia on sacroiliac joint (SIJ) MRI at baseline is associated with spinal radiographic progression in axSpA patients.

Objectives: So in this study, we investigated for propensity to fat metaplasia on SIJ in axSpA patients.

Methods: The 357 patients who fulfilled the ASAS axSpA criteria were enrolled. All underwent MRI on Slj with T2 MR image, T1 fat suppressed with enhanced and short $\mathrm{T}$ inversion recovery (STIR) image at baseline and lumbar spine radiographs at baseline and after 2 years. Inflammatory and structural lesions on SIJ MRI was scored using the SPondylo Arthritis Research Consortium of Canada (SPARCC) method. spinal radiographs were scored using the Stoke AS Spina Score (SASSS). Multivariate logistic regression analysis was performed to identify for propensity to fat metaplasia on SIJ in axSpA patients.

Results: Among the 357 patients on baseline SIJ MRI finding, 182 patients showed fat metaplasia on SIJ, 148 patients showed erosion and 27 patients showed ankylosis. Propensity to fat metaplasia in axSpA patients showed the male, HLA-B27 negative, smoking, back pain onset time within 6-12 months at time of diagnosis, uveitis, peripheral arthritis, compared to erosion and anylosis on SIJ in axSpA patients. The patient with fat metaplasia or ankylosis on SIJ at baseline showed increased SASSS but there was no significant change in SPARCC over 2 years. univariate logistic regression analysis showed back pain onset time within 6-12 months at time of diagnosis and uvitis as a significant predictors of fat metaplasia. multivariated logistic analysis showed back pain onset time within 6-12 months at time of diagnosis as an affecting factor for fat metaplasia on SIJ (OR,5.67; 95\% Cl 4.71-17.95).

Abstract THU0270 - Table 1. The radiographic spinal progression over 2 years according to structural lesion in the sacroiliac joints observed on baseline MRI

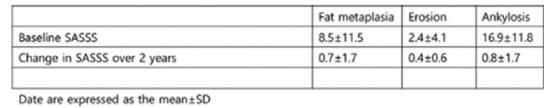

Abstract THU0270 - Table 2. Univariate and multivariate analysis of affecting factor for fat metaplasia on SIJ

\begin{tabular}{|c|c|c|c|c|}
\hline \multirow{2}{*}{ variables } & \multicolumn{2}{|c|}{ univariated analysis } & \multicolumn{2}{|c|}{ Multivariated analysis } \\
\hline & OR(95\%) & p-value & OR(95\%) & p-value \\
\hline $\begin{array}{l}\text { Age at time of } \\
\text { diagnosis (years) }\end{array}$ & $1.10(1.05-1.15)$ & 0.04 & & \\
\hline HLA-B27 positive & $0.28(0.09-0.94)$ & 0.07 & & \\
\hline Smoking & $0.38(0.15-0.98)$ & 0.06 & & \\
\hline $\begin{array}{l}\text { Back pain within } \\
\text { 6-12months at } \\
\text { time of diagnosis }\end{array}$ & 3.12(0.89-10.91) & 0.02 & $5.67(4.71-1795)$ & 0.03 \\
\hline weetis & $259(1.04-6.44)$ & 0.03 & $2.00(0.47-8.62)$ & 0.07 \\
\hline BASOIA & $1.45(0.89-2.78)$ & 0.05 & & \\
\hline $\begin{array}{l}\text { Peripheral } \\
\text { arthritis }\end{array}$ & $0.32(0.10-1.00)$ & 0.06 & & \\
\hline Elevated ESR & $2.59(1.04-6.44)$ & 0.06 & & \\
\hline Elevated CRP & $2.48(1.00-6.19)$ & 0.06 & & \\
\hline
\end{tabular}

Conclusions: The back pain onset time within 6-12 months at time of diagnosis was affecting factor for propensity to fat metaplasia on SIJ in axSpA patients statistically and fat metaplasia on SIJ was associated with radiographic spinal progression in axSpA patients. so the early detection of fat metaplasia on SIJ in axSpA patients was important to protection of radiographic spinal progression.

\section{REFERENCES :}

[1] Maksymowych, et al. MRI evidence of structural changes in thesacroiliac joints of patients with nonradiographicaxial spondyloarthritis even in the absence of MRI inflammation. Arthritis Research \& Therapy 2017;19:126.

[2] Fat Metaplasia on Sacroiliac Joint Magnetic Resonance Imaging at Baseline Is Associated with Spinal Radiographic Progression in Patients with Axial Spondyloarthritis. Plos oneaugust 201513

Acknowledgements: none

Disclosure of Interest: None declared

DOI: 10.1136/annrheumdis-2018-eular.6062

\begin{tabular}{|c|c|c|c|c|c|c|c|}
\hline $\begin{array}{l}\text { Place of study, year of } \\
\text { publication }\end{array}$ & Subjects & $\begin{array}{l}\text { Female: } \\
\text { male }\end{array}$ & Follow up & Remission & Chronic arthritis & $\begin{array}{l}\text { HLA } \\
\text { B27 }\end{array}$ & $\begin{array}{c}\text { Radiological sacroiliitis } \\
\text { (including } \\
\text { asymptomatic) }\end{array}$ \\
\hline France, 20161 & $62 \operatorname{ReA}$ & $10: 52$ & $45 \mathrm{pt} ; 34$ months & $54 \%$ & $\begin{array}{c}44 \% \text { SpA; } 4 \% \\
\text { PsA }\end{array}$ & $64.3 \%$ & NA \\
\hline Finland, 19972 & $\begin{array}{c}63 \text { reactive salmonella } \\
\text { arthritis }\end{array}$ & $28: 35$ & $50 \mathrm{pt}$; mean 11 years & $\begin{array}{l}\text { Drug free: } \\
31.7 \%\end{array}$ & $28.5 \%$ & $88 \%$ & $13.6 \%$ \\
\hline Helsinki, $2009^{3}$ & $60 \mathrm{ReA}$ & $26: 34$ & 40 at 32 years & $\mathrm{HAQ} 0$ in $15 \%$ & NA & $85 \%$ & $15 \%$ \\
\hline Current study & $61 \mathrm{ReA} / 14 \mathrm{uSpA}$ & $14: 71$ & $\begin{array}{l}85 \mathrm{pt} ; \text { median } \\
2 \text { years }\end{array}$ & Drug free: $35 \%$ & $34 \%$ & $80 \%$ & $8.23 \%$ \\
\hline
\end{tabular}

